\title{
COMUNIDADE, MEIO AMBIENTE E ETNOCIÊNCIA: SABERES LOCAIS NA CONSERVAÇÃO DOS RECURSOS NATURAIS
}

\author{
Eduardo Beltrão de Lucena Córdula ${ }^{1}$ \\ Glória Cristina Cornélio do Nascimento ${ }^{2}$ \\ Reinaldo Paiva Farias de Lucena ${ }^{3}$
}

Resumo: A sociedade contemporânea passa por uma crise ambiental sem precedentes, causadas pela ação antrópica e consumo não sustentável dos recursos naturais. Na busca de mudanças da percepção e das ações da população humana sobre o planeta e o ambiente natural, o conhecimento transgeracional das Comunidades Locais podem restaurar e transformar os saberes e práticas da sociedade para com o meio ambiente, fortalecendo vínculos para a gênese de uma Etnoconservação, que poderá se refletir ao longo do tempo no sistema sócio-político e econômico. Objetivando contribuir para o processo de discussão à cerca da relação ser humano e meio ambiente, com foco do local para o global, este artigo contribui com a etnociência, revelando na importância para inserção destes saberes no sistema educacional, em todos os níveis de ensino, para que estas e as futuras gerações possam discutir e desenvolver a sustentabilidade na manutenção do patrimônio natural.

Palavras-chave: Meio Ambiente; Etnociência; Etnobiologia; Ser Humano; Educação.

\footnotetext{
1 Doutorando (PRODEMA/UFPB). E-mail: ecordula@hotmail.com

${ }^{2}$ Doutora (PRODEMA/UFPB). E-mail: gccornelio@hotmail.com

${ }_{3}$ Professor Doutor (UFPB/CCEN-PRODEMA). E-mail: rlucena@dse.ufpb.br
} 


\section{Introdução}

A sociedade contemporânea enfrenta um paradigma sem precedentes na sua história, em virtude da alta demanda no consumo dos recursos naturais, o que, concomitantemente, acarreta graves impactos ambientais ao planeta (CAPRA, 2006a). Estes, ao longo do tempo, acentuaram-se e, consequentemente, vêm afetando toda a dinâmica natural do meio ambiente, diretamente nas suas teias ecológicas (CAPRA, 2006b; DIAS, 2011). Isto se deve, principalmente, na busca pelo crescimento das cidades, com os processos de urbanização e redução das áreas verdes naturais, das mudanças econômicas e sociais que afetam o modo de vida das populações, influenciadas, principalmente, pelo sistema capitalista, o qual estimula o consumismo para geração de capital e que, por sua vez, aumenta o consumo de bens industrializados (LEFF, 2011). Este processo por sua vez, amplia a demandam na produção destes bens de consumo manufaturados, que demanda mais matéria-prima, oriunda da exploração dos recursos naturais (CAPRA, 2006a; LEFF, 2011). Por sua vez, essa cadeia produtiva industrial necessita também, de mais energia, principalmente elétrica e, assim, gera um ciclo negativo, contínuo e retroalimentável, e que provoca os grandes impactos nos biomas e ecossistemas (LEFF, 2011). Ao mesmo tempo em que todo esse ciclo antrópico está ativo e impactando o planeta, ocorre o distanciamento entre a sociedade e a natureza, e com isto, potencializa os desequilíbrios ambientais (DIAS, 2004a; CAPRA, 2006b).

Nesta ótica de impactos e problemas ambientais, principalmente pósrevolução industrial (séculos XVIII e XIX), e que a humanidade vivência e intitula a algumas décadas de mudanças climáticas (TRIGUEIRO, 2005; CAPRA, 2006a; CÓRDULA; NASCIMENTO, 2012; COSTA et al., 2015), fez com que surgissem levantes das diversas áreas científicas, com estudos para alertar a humanidade de suas ações sobre o planeta (DIAS, 2002, 2004b). A primeira e mundialmente conhecida, foi a obra intitulada "Primavera Silenciosa" de Rachel Carson, com primeira edição em 1962 (CARSON, 1969). A partir desta e somando-se a pesquisas por todo o globo, os conhecimentos gerados trouxeram constatações sobre a relação entre o crescimento da sociedade em detrimento do desenvolvimento, onde o consumismo vai de encontro à conservação dos recursos naturais e genéticos, da qualidade de vida e, assim, continuamente ampliam-se os problemas socioambientais (DIAS, 2002; CAPRA, 2006a; LEF, 2011).

Esses estudos fornecem dados para geração de novas técnicas e tecnologias, que podem ser utilizadas na reversão do quadro de impactos antrópicos causados pela expansão da sociedade (CARRARA, 1996; ARRUDA, 1999; DIEGUES; ARRUDA, 2001; MARQUES, 2001; ALBUQUERQUE, 2010; ALBUQUERQUE et al., 2013; COSTA et al., 2015; NASCIMENTO, 2017). Neste sentido, conceitua-se aqui a concepção de crescimento, como o que designa um alto custo ambiental em favor da expansão da sociedade (quantitativo) e que persisti na atualidade, incentivado pelo modelo econômico capitalista (TRIGUEIRO, 2005; CAPRA, 2006a; LEFF, 2011); enquanto que, o modelo de 
desenvolvimento, permite que a sociedade evolua com equidade e com qualidade de vida na relação ser humano e meio ambiente, proporcionando o manejo adequado da biodiversidade e dos recursos naturais, na busca do desenvolvimento sustentável (DIAS, 2004a, 2011; LEF 2011; BOFF, 2012).

Entender a crise ambiental é, necessariamente, uma busca do redescobrimento do papel do ser humano neste planeta. Fazer com que as comunidades se percebam nesta problemática, e na forma como se relacionam com os biomas e ecossistemas, para que, sensibilizadas, compreendam a necessidade da busca de um equilíbrio sistêmico, que, por sua vez, reduzirá a pressão sobre estes sistemas bióticos e, consequentemente, diminuirá a interferência direta ou indireta na natureza (VASCONCELOS, 2010). Sendo assim, a sociedade passará a exigir do sistema político-econômico, uma utilização racional dos recursos naturais, visando a sua sustentabilidade (DIAS, 2011). E, em termos dinâmicos e efetivos, sustentabilidade é,

(...) o conjunto de processos e ações que se destinam a manter a vitalidade e a integridade da Mãe Terra, a preservação de seus ecossistemas com todos os elementos físicos, químicos e ecológicos que possibilitam a existência e a reprodução da vida, 0 atendimento das necessidades da presente e das futuras gerações, e a continuidade da expansão e a realização das potencialidades da civilização humana em suas várias expressões (BOFF, 2012, p.14).

Portanto, todas as questões ambientais passam pela mudança de percepção da humanidade frente à natureza e a sua própria condição humana (DIAS, 2002), para que, entendendo a natureza não como um recurso, e sim, como patrimônio a ser protegido, pelo seu papel intrínseco na manutenção do fluxo sistêmico do planeta, proporcione a manutenção de todas as formas de vidas (CAPRA, 2006a; MORIN, 2010; VASCONCELOS, 2010).

$\mathrm{Na}$ busca do entendimento das relações do ser humano com a natureza, com vistas à busca da conservação dos recursos naturais e adoção de práticas efetivamente sustentáveis por todos os componentes da sociedade (DIAS, 2004a; CAPRA, 2005, 2006b; FONSECA-KRUEL; SILVA; PINHEIRO, 2005; QUIRINO, 2015). Ressalta-se a importância que o conhecimento das comunidades que apresentam laços específicos cultural e socialmente estabelecidos ao longo do tempo, em virtude de manterem ainda, inter-relações de interdependência nas conexões com a natureza (CARVALHO, 2006; ALBUQUERQUE, 2010; GOMES et al., 2017).

Para tratar destes campos - meio ambiente, comunidade, ser humano e sustentabilidade - é necessário, portanto, adentrar nas Comunidades Tradicionais e Locais, no seu modo de vida e na forma como se relacionam, entre seus integrantes e com o território, na busca de seus conhecimentos e na íntima relação deles com a natureza (ALBUQUERQUE et al., 2013). Necessita- 
se analisar, compreender e registrar seus processos de inter-relações, saberes e práticas, o que nortearão os caminhos para uma nova sociedade tecnológica, humanista e ambiental (CASTETTER, 1944; CARRARA, 1996; ALVES; ALBUQUERQUE, 2010; BOFF, 2012).

Portanto, o objetivo deste artigo é contribuir para esse processo de discussão, na inserção destes saberes Tradicionais/Locais, oriundos de pesquisas e disciplinas de graduação/pós-graduação e, assim, alcancem todo o sistema educacional, nos demais níveis de ensino, com foco do local para o global, para sensibilização e entendimento das inter-relações do ser humano com o meio ambiente.

\section{Comunidade e Ambiente}

Comunidade pela ótica da geografia, é definida por Tuan (1980) como a representação das pessoas que ocupam uma região e nela estabelecem relações específicas e apego afetivo pelo local. Para Luca, Brianezi e Sorrentino (2010), na percepção da educação ambiental, comunidade é o espaço geográfico organizado e ocupado por seres humanos. Segundo Johnson (1997), para a sociologia, comunidade é o espaço onde está inserido um grupo humano com forte apego ao local, gerando o sentimento de pertencimento, no qual se baseia sua cultura, suas relações de interdependência com o ambiente e com o grupo social. Para Grisi (2009, p. 73), comunidade na visão biológica são "todas as populações que ocupam determinado local do meio ambiente. Plantas, animais, bactérias e fungos que vivem num ambiente, interagindo entre si, com composição própria, estrutura, relações ambientais, desenvolvimento e função".

Portanto, comunidade, em vários aspectos e áreas do conhecimento, está relacionada a ambiente, espaço geográfico, cultura, seres humanos e nas relações que se constituem entre si e com a natureza. Percebe-se então, nitidamente dois elementos fundamentais nestas concepções: os sujeitos, que constituem o grupo social (comunidade) e o espaço geográfico, que pode ser designado como a região, que, para alguns autores como Diegues e Arruda (2001), o designam como território.

Comunidade e Território possuem, portanto, similaridades conceituais por agregarem o elemento humano. Para Itaborahy (2015), território é designado como o ambiente geograficamente estabelecido (espaço), no qual a comunidade está inserida e se relaciona ao longo do tempo. Para Coelho Neto (2013), o território é um elemento de interposição de espaço, tempo e pelos sujeitos, construído histórica e socialmente, os quais interagem de forma intraespecífica e exploram todos os seus recursos. Nitidamente entre ambos, está implícito o vínculo afetivo e explicitamente o cultural, temporal e espacial dos sujeitos com o ambiente. Esse apego afetivo, temporal e espacial gera a territorialidade, que une intrinsicamente os grupos humanos ao local, e que, sem este vinculo, a comunidade enquanto territorialidade pode perder sua identidade cultural e social (DIEGUES; ARRUDA, 2001; CÓRDULA, 2014). 
Neste contexto, a comunidade e o território passam a caracterizar a Comunidade Tradicional, que traz a vinculação do tempo e das práticas humanas no território. Brasil (2007, p. 01), a estabelece como sendo,

(...) grupos culturalmente diferenciados e que se reconhecem como tais, que possuem formas próprias de organização social, que ocupam e usam territórios e recursos naturais como condição para sua reprodução cultural, social, religiosa, ancestral e econômica, utilizando conhecimentos, inovações e práticas gerados e transmitidos pela tradição.

Portanto, a expressão Comunidade Tradicional remete à grupos culturalmente estabelecidos e diferenciados em um espaço geográfico, possuindo ligações intrínsecas e de interdependência com o mesmo, obtendo dele os recursos necessários para sua sobrevivência - parcial ou total - e, neste processo ocorre a manifestação de saberes, práticas e ligações espirituais ou místicas com a natureza, e que são transmitidas ao longo do tempo, através das gerações (ancestralidade) (ALBUQUERQUE, 2010; NASCIMENTO, 2013; ALBUQUERQUE; ALVES, 2014).

Para Brandão (2015), a ancestralidade (de geração a geração) é um fator marcante na identificação destas Comunidades Tradicionais. Um fator de destaque é a Transmissão Transgeracional do Conhecimento, que ocorre nos núcleos familiares e/ou sociais, onde os saberes são selecionados e se perpetuam ao longo do tempo, através da oralidade (da cultura, dos recursos naturais e genéticos, dos saberes/práticas, da territorialidade, etc.), e que se refletem através dos ritos e símbolos, frente as situações vivenciadas e nas práticas comportamentais cotidianas (PENSO; COSTA; RIBEIRO, 2008; FALCKE; WAGNER, 2014).

A Comunidade Local difere da Tradicional quanto a territorialidade ancestralidade/pertencimento ao território - devido aos processos de urbanização, que acabam descaracterizando seu modo de vida; ou onde grupos podem migrar por motivos diversos ou serem expulsos de seus territórios originais, formando novos núcleos familiares e em espaços distantes de sua ancestralidade (DIEGUES, 2004). Porém, ao manter os saberes, as práticas e ritos culturais, mantêm também sua cultura e tradições, o que as tornam Comunidades Locais (DIEGUES, 2004; NASCIMENTO, 2013).

Os estudos nestas comunidades vêm sendo desenvolvidos, nas últimas décadas, pela etnociência, que busca registrar a cultura e os saberes destes grupos sociais e as suas relações com o ambiente (CARRARA, 1996; ARRUDA, 1999; SILVEIRA; FARIAS, 2009; ALVES; ALBUQUERQUE, 2010; SOARES et al., 2013; FILHO; MARINHO, 2014; NASCIMENTO, 2017).

Em 2007 no Brasil, foi instituída a Política Nacional de Desenvolvimento Sustentável dos Povos e Comunidades Tradicionais - PNPCT (Lei n. $6.040 / 2007)$, a qual os definem como sendo

revista brasileira educação ambiental 
[...] grupos culturalmente diferenciados e que se reconhecem como tais, que possuem formas próprias de organização social, que ocupam e usam territórios e recursos naturais como condição para sua reprodução cultural, social, religiosa, ancestral e econômica, utilizando conhecimentos, inovações e práticas gerados e transmitidos pela tradição (BRASIL, 2007, p. 1).

\section{E, os Território Tradicionais, como sendo}

[...] os espaços necessários a reprodução cultural, social e econômica dos povos e comunidades tradicionais, sejam eles utilizados de forma permanente ou temporária, observado, no que diz respeito aos povos indígenas e quilombolas, respectivamente, o que dispõem os arts. 231 da Constituição e 68 do Ato das Disposições Constitucionais Transitórias e demais regulamentações (BRASIL, 2007, p. 1).

Para Little (2002), a terminologia "povos", é utilizada ao invés de comunidades, devido a sua importância histórica e de resistência às ocupações humanas urbanas e/ou dos latifúndios da monocultura. Desta forma, o autor reconhece como sendo Povos Tradicionais, os Indígenas, Quilombolas, Caboclos, Caiçaras e Extrativistas. Diegues e Arruda (2001) por sua vez, reconhecem estes mesmos núcleos de cultura/tradição e conectados intrinsicamente à territorialidade, como sendo Comunidades Tradicionais e ainda acrescentam aos já citados, os Jangadeiros, os Sitiantes e Roceiros Tradicionais, Sertanejos/Vaqueiros, Caboclos, Pantaneiros e entre outras, mas, as que não classificam como tais, as denominam como não-tradicionais. Os referidos autores só utilizam o termo "comunidade local", quando fazem menção às comunidades em outros países, mas não utilizam o mesmo termo para as descriminadas no Brasil.

No entanto, o termo comunidade vem sendo utilizado em pesquisas sociais no Brasil desde a década de 1990, motivados pela utilização do movimento social da Pastoral da Terra (SABOURIN, 1999). Em 1992, na Conferência Internacional de Meio Ambiente (Rio 92), é redigida a Declaração do Rio sobre Meio Ambiente e Desenvolvimento, que, em seu Princípio 22, traz a denominação de Comunidade Local em paralelo às Comunidades Tradicionais (BRASIL, 1992a). Em 2001, é instituída a Medida Provisória n. 2.186-16, sobre a Convenção sobre Diversidade Biológica, trazendo em seu texto, no Art. 8, o termo Comunidade Local, porém, ainda sem uma definição concisa (BRASIL, 2001). Recentemente, Medeiros e Albuquerque (2012, p. 21-22) fazem uma referência aos conhecimentos específicos e vinculados ao território, transmitidos pela tradição de determinada parcela de uma população e que estão inseridas em espaços urbanos, rurais etc., como sendo a Comunidade Local.

Portanto, a partir de todo este contexto, a Comunidade Local é definida como: todo agrupamento de pessoas/famílias e detentoras de um conhecimento 
específico sobre crenças e práticas relacionadas com a natureza, podendo ou não estarem vinculadas ao território em que residem, e que perpassam através das gerações todo este arcabouço cultural que as constituem e as possibilitam se diferenciar do restante da sociedade (contos, cânticos, ensinamentos, práticas cotidianas, usos e costumes) (DIEGUES; ARRUDA, 2001; LITTLE, 2002; ALBUQUERQUE, 2010; MEDEIROS; ALBUQUERQUE, 2012).

\section{Etnociência e Comunidades Locais}

A etnociência surge em contraposição a ciência clássica positivista "decorrente das posturas teórico-práticas que subalternizam os conhecimentos quotidianos e desprezam o saber-fazer popular, autóctone ou indígena" (DIAS; JANEIRA, 2005, p. 107), se tornando um campo que possibilitou abertura nas pesquisas científicas, unindo as áreas da antropologia, da sociologia e das ciências naturais, para compreensão da relação do ser humano com o meio ambiente (COSTA, 2008; ALVES; ALBUQUERQUE, 2010) e, a partir do contexto das crenças, práticas e das inter-relações nas comunidades, sejam tradicionais, rurais ou urbanas (MARQUES, 2001; RAMIRES; MOLINA; HANAZAKI, 2007). Para Abílio e Sato (2010, p. 31), o prefixo etno refere-se a forma como os membros de uma comunidade se relacionam, interpretam e transmitem o conhecimento circundante. $\mathrm{E}$, para a etnociência buscar tal registro, utiliza a etnografia, que é "uma modalidade de investigação naturalista, tendo como base a observação e a descrição" (Ibidem, p. 31). Portanto, a etnociência, através da etnografia, registra os saberes tradicionais e locais, "por meio da qual as culturas deixam de ser vistas como conjuntos de artefatos e comportamentos e passam a ser consideradas sistemas de conhecimentos ou de aptidões mentais, como revelados pelas estruturas linguísticas" (SILVA; FRAXE, 2013, p. 1).

$\mathrm{Na}$ busca do etnoconhecimento ao longo das décadas, a etnociência se ramificou em diversas áreas de estudo, principalmente, nas biológicas, com destaque para a etnobiologia, com trabalhos em etnoecologia, etnozoologia e etnobotânica (CASTETTER, 1944; URIBE, 2004; WALTERS et al., 2008; ROCHA-COELHO, 2015). No caso dos estudos botânicos em comunidades Tradicionais, há registros desde o ano de 1860 (MEDEIROS, 2009), realizados em comunidades indígenas no uso de plantas como remédio. Desde esta data, a etnobotânica se formalizou e se estruturou "(...) como área de estudo acadêmica" (Ibidem, p. 41). Segundo Etkin e Ticktin (2010), nos últimos 25 anos, os estudos vêm se aprimorando no campo metodológico, principalmente pelos antropologistas botânicos, para compreensão da amplitude do uso das plantas nas diversas culturas e, consequentemente, sendo adaptados e utilizados pela própria etnobiologia e suas ramificações.

Estes estudos ao longo das décadas traçaram o perfil da interação do ser humano com a natureza, ressaltando sua interdependência em vários níveis, principalmente no biológico, cultural e espiritual (DIEGUES; ARRUDA, 2001; TOLEDO; BARRERA-BASSOLS, 2008). Os etno campos da biologia, estudam especificamente, partes do conhecimento biológico, já que há uma amplitude de saberes, práticas e usos atribuídos aos elementos da natureza (ALVES; 
ALBUQUERQUE, 2010). Por esta razão, Medeiros e Albuquerque (2012), em seu estudo semântico das ramificações da etnobiologia, trazem definições, porém, consideram que ainda em processo de construção (Quadro 1).

Quadro 1: Definições da Etnobiologia e suas ramificações.

\begin{tabular}{|l|l|}
\hline Etnobiologia & $\begin{array}{l}\text { "O estudo das relações entre os organismos vivos e os sistemas culturais" (p. } \\
29)\end{array}$ \\
\hline Etnoecologia & $\begin{array}{l}\text { Consideram como o complexo conjunto das relações dos seres humanos com } \\
\text { o ambiente em habitam (p. 36-37) }\end{array}$ \\
\hline Etnobotânica & $\begin{array}{l}\text { Disciplina que estuda as inter-relações que se estabelecem entre o homem e } \\
\text { as plantas através do tem e em diferentes ambientes" (p. 30) }\end{array}$ \\
\hline Entozoologia & $\begin{array}{l}\text { É considerado como o conhecimento e as tradições ligadas a caça e uso dos } \\
\text { animais (p. 44). }\end{array}$ \\
\hline
\end{tabular}

Fonte: Medeiros e Albuquerque (2012).

Para Toledo e Barrera-Bassols (2008), o etnoconhecimento é o tripé que tem na sua base à territorialidade e em seus alicerces o cosmus, o corpus e a praxis. Nestas comunidades, estes três etnoelementos são marcantes e mantém a unidade e identidade destes povos (DIEGUES; ARRUDA, 2001). O cosmus são as crenças espirituais e ritualísticas de um povo, ligados diretamente aos mitos e lendas locais, que, conjuntamente, alimentam a cultura e o folclore local (TOLEDO; BARRERA-BASSOLS, 2008). O corpus é todo o conhecimento local da população, acerca do ambiente que habita e da sua relação com ele, e na utilização dos seus recursos na obtenção de alimento, medicamentos, moradia e matéria-prima, e que são utilizados na confecção de utensílios, construção de instrumentos, moradias, armadilhas entre outros artefatos de uso individual e/ou coletivo pela comunidade. A praxis é o reflexo do corpus e do cosmus, que é representada pelas pinturas, ornamentação e ritos das Comunidades Tradicionais/Locais (Ibidem). É, portanto, o conjunto das práticas individuais e coletivas na comunidade e que englobam o modo de vida, os costumes e hábitos cotidianos, que são representados pelas atividades de sobrevivência, como da passagem de conhecimentos entre as gerações, através da oralidade e no aprendizado pela imitação/repetição pelos mais jovens do grupo/núcleo familiar (WINKERPRINS; BARRERA-BASSOLS; 2005; NASCIMENTO; NASCIMENTO; CÓRDULA, 2014).

O conjunto destes conhecimentos registrados ao longo do tempo pela ciência, subsidiaram parâmetros para ações e estratégias direcionadas a conservação, manejo e uso sustentável do patrimônio natural. Em sua estrutura, trazem a relação harmônica do uso da natureza de forma sustentável, para as gerações futuras; e, também, em paralelo, como os fatores da ação antrópica predatória e poluidora da sociedade urbana e da monocultura, estão afetando a biodiversidade local destas Comunidades Tradicionais/Locais (ARRUDA, 1999; DIEGUES; ARRUDA, 2001; ALBUQUERQUE, 2010; NASCIMENTO, 2017). 


\section{Conservação dos Recursos Naturais}

A alcunha da terminologia conservação, surge internacionalmente na década de 1980, como sendo a promoção do uso sustentável dos recursos naturais, garantindo assim, a sua proteção, manutenção e restauração para melhoria das populações humanas (DIEGUES, 2000a). Em 1992, o Projeto de Lei $(\mathrm{PL})$ n. 2.892, institui o Sistema Nacional de Unidades de Conservação, ampliando a definição inicial, com destaque à necessidade das futuras gerações (BRASIL, 1992b). Esse mesmo PL é transformado em 2000, em Lei Ordinária de n. 9.985. Desde então, o foco dos órgãos e grupos de estudos ambientais em comunidades humanas, buscam o etnoconhecimento como aporte para manutenção dos recursos naturais. Diegues no ano de 2000, traz em sua obra intitulada "Etnoconservação: novos rumos para a proteção da natureza nos trópicos" (DIEGUES, 2000b), uma mensagem da etnoconservação como atividade de proteção, manutenção e restauração do mundo natural, como indicação para implantação de áreas protegidas. Neste sentido, a etnoconservação vem unindo o Conhecimento Tradicional/Local às práticas sustentáveis de uso do patrimônio natural, para que este, continue a existir ao longo do tempo.

A Etnoconservação, portanto, é uma interface entre várias áreas do conhecimento biológico e da etnociência, que busca em sua essência, estudar e promover "(...) as dinâmicas territoriais e a gestão da biodiversidade/recursos naturais" (MEDERIOS; ALBUQUERQUE, 2012, p. 34), com vistas à sustentabilidade. Esta busca é o desafio do novo milênio, em promover o desenvolvimento com equilíbrio ambiental, redução e reversão dos impactos ambientais causados pela ação humana ao planeta (ALBUQUERQUE, 2010).

Nesta busca de unir os integrantes da sociedade aos conhecimentos ambientais, para gênese da consciência ambiental, nasce outro grande desafio, que é a fragmentação da coletividade e da cooperatividade, o que dificulta o entendimento e formação desta consciência universal em prol da qualidade de vida e da sustentabilidade (CUNHA, 2004; ALBUQUERQUE, 2010).

Para Cunha (2004), a maior dificuldade está na união e na formação da coletividade em prol de um bem maior, pois, a racionalidade do ser humano na atualidade, está em primeiro lugar, na busca de suprir as necessidades individuais, para depois, agir indiretamente de forma coletiva, e, assim, acarreta conflitos perante os verdadeiros interesses da coletividade (comunidade). Neste sentido, as mudanças necessárias a humanidade para proteção e conservação da natureza, passariam por uma mudança de percepção dos sujeitos sobre si mesmos e a coletividade, com foco na sua relação com o planeta e no despertar para a consciência planetária da necessidade de um meio ambiente equilibrado (TRIGUEIRO, 2005).

O caminho para estas mudanças está na formação do sujeito, sensibilizando-o para que alcance uma maturidade cognitiva e de autonomia nesta percepção, para gerar a consciência necessária enquanto entidade individual, mas, pertencente a coletividade, e tornando-o multiplicador em seu 
meio e em sua geração, proporcionando reflexos temporais a curto, médio e longo prazos (DIAS, 2002, 2004a,b; CÓRDULA, 2014). Para alcançar este processo, o campo de atuação é a rede de ensino, na educação básica, que encontrará maior flexibilidade para assimilar estes conhecimentos e formar parcerias com as Instituições de Ensino Superior (IES) para fomento deste processo de sensibilização nas comunidades (NASCIMENTO, 2017).

\section{Etnoconhecimento e Sala de Aula}

O percurso a ser realizado para o início destas mudanças, passa em se trazer à sala de aula o etnoconhecimento acumulado pela etnociência, e, principalmente, da(s) comunidade(s) do entorno da escola. Pois, "(...) constitui uma ponte entre o saber popular e o científico estimulando o resgate do conhecimento tradicional, a conservação dos recursos vegetais e o desenvolvimento sustentável' (FONSECA-KRUEL; SILVA; PINHEIRO, 2005, p. 98).

Para Soldati (2014), etnoconhecimento é a transmissão dos saberes e da cultura, como sinônimo de aprendizagem social, que perpassa entre os sujeitos, por ensino e imitação ao longo do tempo (transgeracional), levando-se em consideração quatro elementos de processamento de aprendizado. $O$ primeiro deles é a Informação é o conhecimento que será transferido; o segundo o Modelo, que é o locutor/narrador que transfere a informação; o terceiro o Aprendiz, que é quem recebe e ressignifica pelo aprendizado a(s) informação(s) e; em quarto, o Contexto, que é o local onde todo o processo de transmissão do Conhecimento Local ocorre (ambiental e social) (Ibidem).

As grandes contribuições para que o etnoconhecimento ligados a natureza possam fluir por todos na comunidade e entre as comunidades, está na Etnobiologia e suas subdivisões - Etnobotânica, Etnoecologia, Etnozoologia etc., que através dos estudos dos cosmus, corpus e praxis nas Comunidades Locais, estão sendo revertidos para a educação e em todos os níveis de ensino - do básico à formação acadêmica - proporcionando o maior conhecimento e entendimento das relações harmoniosas e de interpendência sistêmica, com promoção de efetivos componentes de desenvolvimento sustentável (FONSECA-KRUEL; SILVA; PINHEIRO, 2005; COSTA, 2008; ROSA; OREY, 2014).

Naturalmente, estes campos etno biológicos passaram a ser organizados e estruturados em forma de disciplinas acadêmicas, nas Instituições de Ensino Superior (IES), como áreas de estudos, provenientes de pesquisas nas diversas comunidades e das suas inter-relações com o meio ambiente (ALVES; ALBUQUERQUE, 2010). Em pesquisa realizada no Brasil, Fonseca-Kruel et al. (2005) identificaram 13 IES, nas regiões Sudeste e Nordeste, que continham em sua matriz curricular a etnobotância como disciplina formal (obrigatório ou optativa). Desde então, a quantidade de disciplinas formais não só de etnobotância, bem como etnoecologia e etnobiologia, vêm crescendo nas IES, tanto nos cursos de graduação como pós-graduação (OLIVEIRA et al., 2009;

Revbea, São Paulo, V. 13, № 2: 85-103, 2018. 
BAPTISTA, 2015). A partir destas inserções nas IES, como disciplina formal ou como optativa de graduação e/ou programas de pós-graduação (Quadro 2), o etnoconhecimento das Comunidades Tradicionais e Locais, integram à formação dos profissionais.

Quadro 2 - Disciplinas e programas de pós-graduação das ramificações da etnociência ligadas aos conhecimentos sobre os recursos naturais ( $G$ = graduação; $P G$ = Pós-graduação).

\begin{tabular}{|c|c|c|c|}
\hline etno & IES & $\begin{array}{l}\text { Nív } \\
\text { el }\end{array}$ & URL \\
\hline \multirow[t]{7}{*}{ Etnobiologia } & UnB & G & $\begin{array}{l}\text { https://matriculaweb.unb.br/graduacao/disciplina.aspx?cod=2054 } \\
78\end{array}$ \\
\hline & UNIR & $\mathrm{G}$ & $\begin{array}{l}\text { http://www.lic.cienciasbiologicas.unir.br/downloads/3618_1801_ } \\
\text { ementa_etnobiologia_opt.pdf }\end{array}$ \\
\hline & PUC-Rio & G & $\begin{array}{l}\text { https://www.puc- } \\
\text { rio.br/ferramentas/ementas/ementa.aspx?cd=BIO1011 }\end{array}$ \\
\hline & $\begin{array}{l}\text { UNEVAS } \\
T\end{array}$ & G & http://portais.univasf.edu.br/biologia/pud_etnobio_2017-1.pdf \\
\hline & UFRPE & $P G$ & http://ww2.pgetno.ufrpe.br/ \\
\hline & INPA & $P G$ & $\begin{array}{l}\text { http://www.ppginpa.eco.br/documents/ementas/ECO\%20077_Et } \\
\text { nobiologia.pdf }\end{array}$ \\
\hline & UNESC & $P G$ & http://www.unesc.net/portal/blog/ver/314/30943 \\
\hline $\begin{array}{l}\text { Etnobiologia e } \\
\text { Etnoecologia }\end{array}$ & UNEMAT & $P G$ & $\begin{array}{l}\text { http://portal.unemat.br/media/oldfiles/ppgca/docs/disc_etnobiolo } \\
\text { gia_e_etnoecologia.pdf }\end{array}$ \\
\hline $\begin{array}{l}\text { Etnobotânica e } \\
\text { Etnobiologia }\end{array}$ & UFMT & $P G$ & $\begin{array}{l}\text { http://www.ufmt.br/ppgcfa/arquivos/18d1d8045d384fafd87f1c819 } \\
\text { 6779c24.pdf }\end{array}$ \\
\hline Etnoecologia & $\begin{array}{l}\text { PRODEM } \\
\text { A/UFPB }\end{array}$ & $P G$ & $\begin{array}{l}\text { http://www.prpg.ufpb.br/prodema/contents/menu/disciplinas/dout } \\
\text { orado }\end{array}$ \\
\hline \multirow[t]{4}{*}{ Etnobotânica } & UERJ & $\mathrm{G}$ & $\begin{array}{l}\text { http://www.ffp.uerj.br/arquivos/dcien/eletivas_uni/ementa_Etnob } \\
\text { ot\%E2nica\%20e\%20Botanica\%20Economica.pdf }\end{array}$ \\
\hline & UNESP & $P G$ & $\begin{array}{l}\text { http://www.fca.unesp.br/Home/PosGraduacao/Horticultura/Etnob } \\
\text { otanica.pdf }\end{array}$ \\
\hline & $\begin{array}{l}\text { BIONORT } \\
\text { E (UFAM) }\end{array}$ & $P G$ & $\begin{array}{l}\text { http://www.bionorte.org.br/programa-de-pos- } \\
\text { graduacao/disciplinas/detalhes.htm?idd=107 }\end{array}$ \\
\hline & UFRPE & $P G$ & $\begin{array}{l}\text { http://ww2.pgb.ufrpe.br/br/content/pbot7310- } \\
\text { etnobot\%C3\%A2nica }\end{array}$ \\
\hline $\begin{array}{l}\text { Etnobotânica do } \\
\text { Cerrado }\end{array}$ & $\begin{array}{c}\text { UnB } \\
\text { Cerrado }\end{array}$ & $\mathrm{G}$ & $\begin{array}{l}\text { https://unbcerrado.wixsite.com/centrounbcerrado/disciplinas-de- } \\
\text { graduacao }\end{array}$ \\
\hline $\begin{array}{l}\text { Etnobotânica e } \\
\text { Botânica } \\
\text { Econômica }\end{array}$ & UFRRJ & $\mathrm{G}$ & http://r1.ufrrj.br/wp/ib/files/2013/04/Microsoft-Word-IB-611.pdf \\
\hline \multirow{2}{*}{$\begin{array}{l}\text { Etnobotânica e } \\
\text { Etnofarmacologi } \\
\text { a }\end{array}$} & UNIFESP & $\mathrm{G}$ & http://www.cee.unifesp.br/etnofarmacologia.htm \\
\hline & UFRPE & $P G$ & $\begin{array}{l}\text { https://www.ufpe.br/documents/39690/725297/ETNOBOTANICA } \\
\text { +E+ETNOFARMACOLOGIA.pdf/d1273b36-9d6c-46cd-86be- } \\
\text { 9f472a11ca40 }\end{array}$ \\
\hline $\begin{array}{ll}\text { Taxonomia } & \text { e } \\
\text { etnobotânica }\end{array}$ & UFPB & PG & $\begin{array}{l}\text { https://sigaa.ufpb.br/sigaa/public/programa/secao_extra.jsf?lc=pt } \\
\text { _BR\&id=1882\&extra=65375500 }\end{array}$ \\
\hline Etnozoologia & UFES & $P G$ & $\begin{array}{l}\text { http://www2.uefs.br:8081/zoologia/Ementas/Zoo009_Etnozoologi } \\
\text { a2014.doc }\end{array}$ \\
\hline $\begin{array}{l}\text { Etnoecologia e } \\
\text { Conservação }\end{array}$ & UFERSA & $\mathrm{G}$ & $\begin{array}{l}\text { https://ppgec.ufersa.edu.br/wp- } \\
\text { content/uploads/sites/53/2014/10/Programa-Etnoecologia-e- } \\
\text { Conservacao.pdf }\end{array}$ \\
\hline $\begin{array}{l}\text { Etnoconservaçã } \\
\text { o }\end{array}$ & UESC & $P G$ & $\begin{array}{l}\text { http://www.ecologiauesc.com.br/ckfinder/userfiles/files/Ementa_ } \\
\text { EtnoconservacaoOK.pdf }\end{array}$ \\
\hline $\begin{array}{l}\text { Etnoecologia e } \\
\text { Etnoconservaçã } \\
\text { o Pesqueira }\end{array}$ & $\begin{array}{l}\text { UNISANT } \\
\text { A }\end{array}$ & $\mathrm{G}$ & http://www.unisanta.br/arquivos/isoladas4.pdf \\
\hline
\end{tabular}

Fonte: Pesquisa Google - Palavras-Chave: Disciplina Etno - 2012 a 2017.

Revbea, São Paulo, V. 13, № 2: 85-103, 2018. 
O levantamento resultou em 23 ocorrências com dados disponíveis na internet. Destes, 19 IES a nível de graduação e/ou programas de pósgraduação, sendo que, destas, com 10 disciplinas de graduação e $13 \mathrm{com}$ disciplinas/programas de pós-graduação, as quais poderão debater sobre 0 etnoconhecimento relacionado a natureza: importância e aplicabilidade, metodologias e questões éticas e bioéticas, tipos de pesquisas e áreas potenciais de estudo, para que tragam resultados e assim, todo este arcabouço seja inserido na Educação Básica, em suas disciplinas (ensino fundamental e médio). Desta forma, corrobora com os estudos de Fonseca-Kruel et al. (2005), da crescente inserção nas IES de pesquisas/estudos, disciplinas/programas não só nas graduações e também, nas pós-graduações.

Especificamente nas graduações de licenciatura, estas etno-disciplinas podem alcançar os demais estratos do sistema educacional, chegando na forma de conteúdos didáticos/paradidáticos inseridos pelos professores nas disciplinas da educação básica (Fundamental e Médio) (SIQUEIRA, 2012; PEREIRA; SIQUEIRA, 2013; SILVA et al., 2014; ALMEIDA et al., 2016; SENA et al., 2016; COSTA et al., 2015; FERREIRA et al., 2017). E, como consequência, esta inserção na formação dos professores, trará mudanças curriculares nas disciplinas escolares, em um processo contínuo retroalimentável (OLIVEIRA JÚNIOR; SATO, 2006; TRÉZ, 2011). Por sua vez, estes conhecimentos podem ser acessados pelas escolas inseridas nestas comunidades, através dos Projetos Pedagógicos Interdisciplinares (PPIs) e desenvolvidos por estes professores(as), que buscarão nas pessoas das comunidades, os informantes e detentores dos saberes locais, com valorização da cultura e do etnoconhecimento, para estas e as futuras gerações (ALMEIDA et al., 2016).

Algumas práticas pedagógicas neste sentido já foram desenvolvidas e publicadas por professores e pesquisadores nas/das escolas, com foco no Conhecimento Local sobre os diversos usos de plantas (OLGUIN et al., 2007; SILVEIRA; FARIAS, 2009; KOVALSKI; OBARA, 2013; SILVA; MARISCO, 2013; SIQUEIRA; PEREIRA, 2014), de animais (CABRAL, 2009; BRUNO; KRAEMER, 2010; ARAÚJO; KRAEMER; MURTA, 2011; OLIVEIRA; SOUZA, 2014; RODRIGUES, 2015) e da cultura/folclore (ABIB, 2004; FREIRE, 2006; MOREIRA; CANDAU, 2007). Estes saberes registrados pelos educandos das escolas, possibilitarão a sensibilização dos integrantes da própria comunidade escolar e do seu entorno, além do resgate e valorização de saberes e valores culturais/sociais, que poderão se refletir em atitudes de proteção ao patrimônio natural (etnoconservação).

Portanto, manter as culturas e saberes locais vívidos entre as gerações é um dever não só da própria comunidade, e também do Estado e das Instituições de Ensino Superior, através de suas pesquisas/estudos nestas áreas, para registro, valorização e perpetuação do etnoconhecimento e da Cultura Local, como da relação ser humano-natureza nos sistemas bióticos equilibrados e onde ocorram o uso sustentável de seu patrimônio natural (BAPTISTA, 2007; QUIRINO, 2015). 


\section{Conclusões}

A crise ambiental que o planeta vem passando é fruto da ação humana, na utilização da natureza, que a entende como recurso a ser explorado incessantemente, para suprir as demandas de consumo da sociedade. Reverter esta situação exige esforços de toda a sociedade, buscando nas relações harmônicas do ser humano com a natureza, na mudança do quadro atual de desequilíbrios ambientais.

$\mathrm{Na}$ gênese de uma nova percepção do ser humano na sua relação com o meio ambiente, a etnociência através de suas ramificações que pesquisam esta relação, principalmente na etnobiologia, através do registro dos saberes (corpus), das práticas (praxis) e dos mitos (cosmus), dão suporte para entendimento das relações harmônicas e que conduzirão ao processo de sensibilização da sociedade, para promoção das mudanças necessárias. Portanto, os etnoconhecimentos estudados, analisados e convertendo-se em conteúdos e atividades didáticas nas disciplinas curriculares das instituições de ensino superior e da educação básica, promoverão não só a mudança de percepção necessária pelos processos de sensibilização ambiental, e também, atividades que registrem, valorizem e a cultura, os saberes e práticas, em um contínuo processo que se retroalimenta ao longo do tempo, culminando para uma etnoconservação, com vistas ao desenvolvimento sustentável, através destas Comunidades Tradicionais e Locais.

\section{Agradecimentos}

As comunidades tradicionais e locais que continuam a multiplicar entre as gerações seus saberes, práticas e mitos, mantendo viva sua cultura imaterial e contribuindo para ciência, através da partilha deste universo, para que toda sociedade compreenda a relação entre o ser humano e a natureza.

\section{Referências}

ABIB, P.R.J. Capoeira Angola: cultura popular e o jogo dos saberes na roda. Tese de Doutorado, Programa de Pós-Graduação em Ciências Sociais Aplicadas à Educação, UNICAMP, Campinas-SP, 2004.

ABÍLIO, F.J.P.; SATO, M.S. Métodos e Técnicas de coleta de dados em Pesquisas com Educação Ambiental. In: ABÍLIO, F.J.P.; SATO, M. Educação Ambiental: do currículo da educação básica às vivências educativas no contexto do semiárido paraibano. João Pessoa, PB: Ed. Universitária da UFPB, 2010, p. 17-56.

ALBUQUERQUE, U.P. Etnobotânica Aplicada à Conservação da Biodiversidade. In: ALBUQUERQUE, U.P.; LUCENA, R.F.P.; CUNHA, L.V.F.C. (Org.) Métodos e Técnicas na Pesquisa Etnobiológica e Etnoecocológica. Recife, PE: NUPPEA, 2010, p. 351-364. 
ALBUQUERQUE, U.P. et al. The current status of ethnobiological research in Latin America: gaps and perspectives. Journal of Ethnobiology and Ethnomedicine, v. 9, n. 72, p. 2-9, 2013.

ALBUQUERQUE, U.P.; ALVES, A.G.C. $O$ que é Etnobiologia? In: ALBUQUERQUE, U.P. (Org.). Introdução à Etnobiologia. Recife, PE: NUPPEA, 2014, p.17-22.

ALMEIDA, H.A. et al. Etnoecologia em sala de aula: os entraves para integrar conhecimentos tradicionais ao conhecimento científico. In: Congresso Internacional da Diversidade do Semiárido, 1., Campina Grande-PB, 2016. Anais... Campina Grande, PB: UEPB, 2016.

ALVES, A.G.C.; ALBUQUERQUE, U.P. "Ethno what?" Terminological problems in ethnocience with a special emphasis on the Brazilian context. In: ALBUQUERQUE, U.P.; HANAZAKI, N. (Eds.). Recent Developments and Case Studies in Ethnobotany. Recife, PE: NUPEEA, 2010, p. 67-80.

ARAÚJO, R.T.N.; KRAEMER, B.M.; MURTA, P.F.O. Percepções ambientais e concepções de estudantes do ensino fundamental de Belo Horizonte/MG sobre tubarões. e-Scientia, Belo Horizonte-MG, v. 4, n. 1, p. 69-79, 2011.

ARRUDA, R. "Populações Tradicionais" e a Proteção dos Recursos. Ambiente \& Sociedade, São Paulo, Ano II, n. 5, jul./dez. 1999.

BAPTISTA, G.C.S. A Contribuição da Etnobiologia para o Ensino e a Aprendizagem de Ciências: estudo de caso em uma escola pública do estado da Bahia. Dissertação de Mestrado, Programa de Pós-Graduação em Ensino, Filosofia e História das Ciências. Salvador, BA: UFBA, 2007.

BOFF, L. Sustentabilidade: o que é - o que não é. Petrópolis, RJ: Vozes, 2012.

BRANDÃO, C.R. A Comunidade Tradicional. NUPAUB, 2015. Disponível em: $<$ http://nupaub.fflch.usp.br/sites/nupaub.fflch.usp.br/files/a\%20comunidade\%20tr ad160.pdf>. Acesso em: 10 dez. 2017.

BRASIL. Agenda 21 - Conferência das Nações Unidas sobre Meio Ambiente e Desenvolvimento. Rio de Janeiro: MMA, ONU, 1992a.

BRASIL. Projeto de Lei n. 2.892, de 01 de janeiro de 1992. Brasília, DF: Senado Federal, 1992b.

BRASIL. Medida Provisória n. 2.186-16, de 23 de agosto 2001. Brasília, DF: Senado Federal, 2001.

BRASIL. Decreto n. 6.040 de 07 de fevereiro de 2007 - Institui a Política Nacional de Desenvolvimento Sustentável dos Povos e Comunidades Tradicionais. Brasília, DF: Casa Civil, 2007.

BRUNO, M.; KRAEMER, B.M. Percepções de estudantes da $6^{\underline{a}}$ série $\left(7^{\circ}\right.$ ano) do "'Ensino Fundamental" em uma escola pública de Belo Horizonte, MG sobre morcegos: uma abordagem etnozoológica. e-Scientia, Belo Horizonte-MG, v. 3, n. 2, p. 42-50, 2010.

CABRAL, T.C. Etnozoologia: percepção ambiental de alunos da educação básica de escolas inseridas em área predominantemente urbana e rural. TCC, Curso de Ciências Biológicas, UNISALLE, Canoas-RS, 2009.

Revbea, São Paulo, V. 13, № 2: 85-103, 2018. 
CAPRA, F. As Conexões Ocultas: ciência para uma vida sustentável. São Paulo: Cultrix, 2005.

CAPRA, F. O Ponto de Mutação: a ciência, a sociedade e a cultura emergente. 10. reimp. São Paulo: Cultrix, 2006a.

CAPRA, F. A Teia da Vida: uma nova compreensão científica dos sistemas vivos.10. reimp. São Paulo: Cultrix, 2006b.

CARSON, R. Primavera Silenciosa. 2. ed. São Paulo: Edições Melhoramentos, 1969.

CARVALHO, L.M.M. Estudos de etnobotânica e botânica económica no Alentejo. Coimbra, Portugal, 2006. Disponível em: $<$ http://hdl.handle.net/10316/2078>. Acesso em: 20 nov. 2017.

CARRARA, E. Classificaçõe émicas da natureza - a etnobiologia no Brasil e a socialização das espécies naturais. Cadernos de Campo, São Paulo, v. 5, n. 56, 1996.

CASTETTER, E.F. The Domain of Ethnobiology. The American Naturalist, v. 78, n. 775, p. 158-170, mar.-abr. 1944.

COELHO NETO, A.S. Componentes definidores do conceito de território: a multiescalaridade, a multidimensionalidade e a relação espaço-poder. Geographia, v. 15, n. 29, p.23-52, 2013.

CÓRDULA, E.B.L. Percepção e Formação do Sujeito Ambiental: mudanças no paradigma atual. Gaia Scientia, João Pessoa-PB, UFPB, v. 8, n. 1, p.150-155, 2014.

CÓRDULA, E.B.L.; NASCIMENTO, G.C.C. Hermenêutica Ambiental e Educação: tecendo saberes e pensamentos. In: CANANÉA, F.A. (Org.). Educação Dialogada. João Pessoa, PB: IMPRELL, 2012, p. 63-80.

COSTA, R.G.A. Os Saberes Populares da Etnociência no Ensino das Ciências Naturais: uma proposta didática para aprendizagem significativa. Revista Didática Sistêmica, Rio Grande-RS, v. 8, jul.-dez. 2008.

COSTA, C.J.S.; LIMA, R.A.; CÓRDULA, E.B.L.; NASCIMENTO, G.C.C. Educação Ambiental como Instrumento da Gestão do Distrito dos Mecânicos em Campina Grande, Estado da Paraíba, Brasil. Gaia Scientia, João Pessoa-PB, UFPB, v. 9, n. 1, p.7-16, 2015.

CUNHA, L.H. Da "Tragédia dos Comuns" à Ecologia Política: perspectivas analíticas para o manejo comunitário dos recursos naturais. Raízes, Campina Grande-PB, v.23, n. 1-2, p. 10-26, jan-dez. 2004.

DIAS, G.F. Pegada Ecológica e Sustentabilidade Humana. São Paulo: Gaia, 2002.

DIAS, G.F. Educação Ambiental: princípios e práticas. 9. ed. São Paulo: Gaia, 2004a.

DIAS, G.F. Ecopercepção: um resumo didático dos desafios socioambientais. São Paulo: Editora Gaia, 2004b. 
DIAS, A.S.; JANEIRA, A.L. Entre ciências e Etnociências. Episteme, Porto Alegre, n. 20, Suplemento Especial, p.107-127, jan.-jun. 2005.

DIAS, R. Gestão ambiental: responsabilidade social e sustentabilidade. São Paulo; Atlas; 2011.

DIEGUES, A.C. A Etnoconservação da Natureza: enfoques alternativos. In: DIEGUES, A.C. Etnoconservação: novos rumos para a proteção da natureza nos trópicos. 2. ed. São Paulo: Nupaub/HUCITEC, 2000a, p. 01-46.

DIEGUES, A.C. Etnoconservação: novos rumos para a proteção da natureza nos trópicos. 2. ed. São Paulo: Nupaub/HUCITEC, 2000b.

DIEGUES, A.C. A Mudança como Modelo Cultural: o caso da cultura caiçara e a urbanização. In: DIUEGUES, A C. (Org.). Enciclopédia Caiçara. v. 1. São Paulo: HUCITEC: NUPAUB: CEC/USP, 2004, p.21-48.

DIEGUES, A.C.; ARRUDA, R.S.V. (Org.). Saberes Tradicionais e Biodiversidade no Brasil. São Paulo: MMA-USP, 2001.

ETKIN, N.L.; TICKTIN, T. Advancing an Ethno-Ecological Perspective that Integrates Theory and Method in Ethnobotany. In: ALBUQUERQUE, U. P.; HANAZAKI, N. (Eds.). Recent Developments and Case Studies in Ethnobotany. Recife, PE: NUPEEA, 2010, p.33-57.

FALCKE, D.; WAGNER, A. A Dinâmica Familiar e o Fenômeno da Transgeracionalidade: definição de conceitos. In: WAGNER, A. (Org.). Como se Perpetuar a Família?: a transmissão dos modelos familiares. Porto Alegre: EDIPUCRS, 2014, p. 25-46.

FERREIRA, G.; CAMPOS, M.G.P.A.; PEREIRA, B.L.; SANTOS, G.B. A etnobotânica e o ensino de botânica do ensino fundamental: possibilidades metodológicas para uma prática contextualizada. FLOVET, Cuibá-MT, v. 1, n. 9, p. 86-101, 2017.

FILHO, J.A.L.; MARINHO, M.G.V. Levantamento da diversidade e uso das plantas medicinais utilizadas por moradores do município de Puxinanã, PB, Brasil. Gaia Scientia, Edição Especial - Comunidades Tradicionais, João Pessoa-PB, p. 229-249, 2014.

FONSECA-KRUEL, V.S.; SILVA, I.M.; PINHEIRO, C.U.B. O Ensino Acadêmico da Etnobotânica no Brasil. Rodriguesia, Rio de Janeiro, v. 56, n. 87, p. 97-106, 2005.

FREIRE, I.M. Acesso à informação e identidade cultural: entre o global e o local. Ciência da Informação, Brasília, v. 35, n. 2, p. 58-67, maio-ago. 2006.

GOMES, G.C.; MEDEIROS, C.A.B.; GOMES, J.C.C.; BARBIERI, R.L. A Crise paradigmática nas ciências de identificação de plantas e a valorização da etnobotânica. Revista Agrogeoambiental, Pouso Alegre-RS, v.9, n.1, 2017.

GRISI, B. Glossário de Ecologia. 3. ed. 5. reimp. João Pessoa, PB: Ed. Universitária da UFPB, 2009. 
ITABORAHY, N.Z. A Geografia, o Conceito do Território e os Processos de Territorialização das Comunidades Quilobomlas: Primeiras Aproximações. Disponível em: <http://www.ufjf.br/nugea/files/2010/09/A-Geografia-o-conceitodo-territ\%C3\%B3rio-e-os-processos-de-territorializa\%C3\%A7\%C3\%A3o-dascomunidades-quilombolas.pdf $>$. Acesso em: $11 \mathrm{dez} .2015$.

JOHNSON, A.G. Dicionário de Sociologia. Rio de Janeiro: Jorge Zahar Editores, 1997.

KOVALSKI, M.L.; OBARA, A.T. O estudo da etnobotânica das plantas medicinais na escola. Ciências \& Educação, Bauru-SP, v. 19, n. 4, p. 911-927, 2013.

LEFF, H. Saber Ambiental: sustentabilidade, racionalidade, complexidade, poder. Petrópolis, RJ: Vozes, 2011.

LITTLE, P.E. Etnodesenvolvimento local: autonomia cultural na era do neoliberalismo global. Tellus, Campo Grande-MS, ano 2, n. 3, p. 33-52, out. 2002.

LUCA, A.Q.; BRIANEZI, T.; SORRENTINO, M. O Conceito de 'Comunidade' na Educação Ambiental. In: Encontro Nacional da ANPPAS, 5., Florianópolis-SC, 2010. Anais... Florianopolis-SC: ANPPAS, 2010. Disponível em: <http://www.anppas.org.br/encontro5/cd/artigos/GT6-179-112-

20100902100727.pdf>. Acesso em: 12 dez. 2015.

MARQUES, J.G. Pescando pescadores: ciência e etnociência em uma perspectiva ecológica. 2. ed. São Paulo: NUPAUB, USP, 2001.

MEDEIROS, M.F.T. Etnobotânica Histórica: princípios e procedimentos. Recife, PE: NUPEEA, 2009.

MEDEIROS, M.F.T.; ALBUQUERQUE, U.P. Dicionário Brasileiro de Etnobiologia e Etnoecologia. Recife, PE: NUPPEA, 2012.

MOREIRA, A.F.B.; CANDAU, V.M. Currículo, Conhecimento e Cultura. Salto para o Futuro, Brasília, n. 17, p. 20-29, set. 2007.

MORIN, E. A cabeça bem-feita: repensar a reforma, reformar o pensamento. Rio de Janeiro: Bertrand Brasil, 2010.

NASCIMENTO, G.C.C. Mestre dos Mares: o saber do território, o território do saber na pesca artesanal. In: CANANÉA, F. A. Sentidos de Leitura: sociedade e educação. João Pessoa-PB: IMPRELL, 2013, p. 57-68.

NASCIMENTO, M.E.C.; NASCIMENTO, G.C.C.; CÓRDULA, E.B.L. Cultura e a oralidade nos contos tradicionais. Revista Educação Pública, Rio de Janeiro, v. 14, n. 20, jun. 2014.

NASCIMENTO, G.C.C. O Conhecimento Local e suas Contribuições para a Conservação. Revista Educação Ambiental em Ação, Novo Hamburgo-RS, v. XV, n. 59, 2017. Disponível em: <http://revistaea.org/artigo.php?idartigo=2659>. Acesso em: 19 jun. 2017.

OLIVEIRA JÚNIOR, S.B.; SATO, M. Educação Ambiental e Etnoconhecimento: parceiros para a conservação da diversidade de aves pantaneiras. Ambiente \& Educação, Rio Grande-RS, v. 11, p. 125-134, 2006. 
OLIVEIRA, F.C.; ALBUQUERQUE, U.P.; FONSECA-KRUEL, V.S.; HANAZAKI, $\mathrm{N}$. Avanços nas pesquisas etnobotânicas no Brasil. Acta Botanica Brasilica, Belo Horizonte-MG, v. 23, n. 2, p. 590-605, 2009.

OLIVEIRA, L.S.; SOUZA, M.L. Articulando o ensino de zoologia com a etnozoologia: análise de uma proposta educativa com estudantes do ensino fundamental. Revista SBEnBio, n. 7, p. 5470-5481, out. 2014.

OLGUIN, C.F.A.; CHUNHA, M.B.; DAL BOSCO, C.B.; SVHNEIDER, M.B.; BOCARDI, J.M.B. Plantas medicinais: estudo etnobotânico dos distritos de Toledo e produção de material didático para o ensino de ciências. Act Scientiarum, Human and Social Sciences, v. 29, n. 2, p. 205-209, 2007.

PENSO, M.A.; COSTA, L.F.; RIBEIRO, M.A. Aspectos teóricos da transmissão transgeracional e do genograma. In: PENSO, M.A.; COSTA, L.F. (Orgs.). A Transmissão Geracional em Diferentes Contextos: da pesquisa à intervenção. São Paulo: Summus, 2008, p. 09-23.

PEREIRA, S.M.; SIQUEIRA, A.B. Abordagem Etnobotânica no Ensino de Biologia. In: Simpósio de Formação de Professores, 5., Tubarão-SC, 2013. Anais... Tubarão, SC: UFSC, 2013.

QUIRINO, G.S. Saber científico e etnoconhecimento: é bom pra quê? Ciência e Educação, Bauru, v. 21, n. 2, p. 273-283, 2015.

RAMIRES, M.; MOLINA, S.M.G.; HANAZAKI, N. Etnoecologia caiçara: o conhecimento dos pescadores artesanais sobre aspectos ecológicos da pesca. Biotemas, Florianópolis-SC, v. 20, n. 1, p. 101-113, 2007.

ROCHA-COELHO, F.B. Etnobiologia. UESC/NEAD. Disponível em: $<$ http://nead.uesc.br/arquivos/Biologia/modulo 8bloco 1/uni etnobiologia/materi al apoio/modulo etnobiologia.pdf>. Acesso em: 06 ago. 2015.

RODRIGUES, A. L. F. Conhecimento etnozoológico de estudantes de escolas públicas sobre os mamíferos aquáticos que ocorrem na Amazônia. Tese de Doutorado, Programa de Pós-graduação em Teoria e Pesquisa do Comportamento, UFPA, Belém-PA, 2015.

ROSA, M.; OREY, D. C. Aproximando Diferentes Campos de Conhecimento em Educação: a etnomatemática, a etnobiologia e a etnoeologia. VIDYA, Santa Maria, v. 34, n. 1, p. 1-14, jan./jun. 2014.

SABOURIN, E. Ação coletiva e organização dos agricultores no Nordeste semiárido. Congresso da SOBER, 37., ago. 1999, Foz de Iguaçu-PR. Anais... Foz de Iguaçu-PR: SOBER, 1999.

SENA, S.A.S. et al. Etnobotânica: um diálogo interdisciplinar entre as plantas medicinais e o ensino de Química e Biologia. In: Encontro Nacional de Ensino de Química (ENEQ), 18., Florianópolis-SC, 2016. Anais... Florianópolis, SC: UFSC/SBQ, 2016.

SIQUEIRA, A.B. Etnobiologia como metodologia no ensino de ciências. In: Simpósio sobre Formação de Professores - SIMFOP, 4., Universidade do Sul de Santa Catarina, Tubarão-SC, 2012. Anais... Tubarão, SC: UFSC, 2012. 
SIQUEIRA, A.B.; PEREIRA, S.M. Abordagem etnobotânica no ensino de Biologia. Rev. Elet. do Mestrado em Educação Ambiental, FURG, v. 31, n. 2, p. 247-260, jul./dez. 2014.

SILVA, F.P.; FRAXE, T.J. Saberes de populações tradicionais: etnociência em processos de bioconservação. Contribuciones a las Ciencias Sociales, España, ago. 2013.2 Disponível em: $<$ www.eumed.net/rev/cccss/25/biodiversidade.html>. Acesso em: 15 dez. 2017.

SILVA, J.A.; AZEVÊDO, E.L.; SILVA, G.M.S.; FRANCISCO, M.M.L.; DIAS, M.A.S. Etnobotânica no Ensino de Biologia. In: Encontro de Iniciação à Docência da UEPB, 4., Campina Grande-PB, 2014. Anais... Campina Grande, PB: UEPB, 2014.

SILVA, T.S.S.; MARISCO, G. Conhecimento etnobotânico dos alunos de uma escola pública no município de Vitória da Conquista/BA sobre plantas medicinais. Biofar, Campina Grande-PB, v. 9, n. 2, p. 62-73, jun./ago. 2013.

SILVEIRA, A. P.; FARIAS, C. C. Estudo Etnobotânico na Educação Básica. Poiésis, Tubarão-SC, v. 2, n. 1, p. 14-31, jan.-jun. 2009.

SOARES, Z.A. et al. Local Botanical Knowledge About Useful Species in a SemiArid Region From Northeastern Brazil. Gaia Scientia, João Pessoa-PB, v. 7, n. 1, p. 80-103, 2013.

SOLDATI, G.T. A Transmissão do Conhecimento Local ou Tradicional e o Uso dos Recursos Naturais. In: ALBUQUERQUE, U.P. Introdução à Etnobiologia. Recife-PE: NUPEEA, 2014, p. 151-156.

TOLEDO, V.M.; BARRERA-BASSOLS; N. La Memoria Biocultural: La importância ecológica de lãs sabidurías tradicionales. Barcelona, Espanha: Icaria Editorial, 2008.

TRIGUEIRO, A. Mundo Sustentável: abrindo espaço na mídia para um planeta em transformação. São Paulo: Globo, 2005.

TRÉZ, T.A. Feyerabend, interculturalismo e etnobiologia: algumas possíveis articulações no ensino de Biologia. Biotemas, Florianópolis-SC, v. 24, n. 3, p. 129-140, set. 2011.

TUAN, Yi-Fu. Topofilia: um estudo da percepção, atitudes e valores do meio ambiente. São Paulo: DIFEL, 1980.

URIBE, L.G.V. Etnoducacion y Etnobiología: uma alternativa? Acta Biologica Colombiana, v. 9, n. 2, p. 67-70, 2004.

VASCONCELOS, M.J.E. Pensamento sistêmico: o novo paradigma da ciência. Campinas, SP: Papirus, 2010.

WALTERS, B.B. et al. Ethnobiology, socio-economics and management of mangrove forests: A review. Aquatic Botany, v. 89, n. 2, p. 220-236, aug. 2008.

WINKERPRINS, A.M.G.A.; BARRERA-BASSOLS, N. Introduction: Ethnoecology. Journal of Latin American Geography, v. 4, n.1, p. 7-8, 2005. 